\title{
Em torno - ruínas de uma cidade em eterna reconstrução
}

\author{
Alexandre Sá Barretto da Paixão' e João Paulo Alvaro Racy"
}

Resumo: Esse artigo pretende investigar as transformações atravessadas pela cidade do Rio de Janeiro durante processo de reforma urbanística preparatória para os Jogos Olímpicos (2016) e a Copa do Mundo (2014), estabelecendo possíveis relações de aproximação e distanciamento com a Reforma Pereira Passos, realizada entre 1902 e 1906. Destruições intencionais que erigiram novos monumentos, consideravelmente questionáveis.

Palavras-chave: Ruína. Gentrificação. Desapropriação. Desterritorialização.

\section{Around - ruins of a city in eternal reconstruction}

\begin{abstract}
This article aims to investigate the transformations that the city of Rio de Janeiro went through during the urban reform process in preparation for the Olympic Games (2016) and the World Cup (2014), establishing possible relations of closeness and distance with the Pereira Passos Reform, carried out between 1902 and 1906. Intentional destruction that erected new monuments, considerably questionable.
\end{abstract}

Keywords: Ruin. Gentrification. Expropriation. Deterritorialization.

I Artista-pesquisador, curador, crítico de arte e psicanalista. Pós-doutorando em História pelo PPGH- UFF. Procientista/UERJ com o projeto As revistas acadêmicas de Artes Visuais. Atual diretor do Instituto de Artes e professor do PPGARTES/UERJ. Sócio da Associação Brasileira de Críticos de Arte. Membro da ANPAP - Comitê de Poéticas Artísticas. Membro da Associação Nacional de História (ANPUH). Docente da Universidade do Estado do Rio de Janeiro - Rua São Francisco Xavier, 524 - Maracanã, Rio de Janeiro - RJ, 20943-000. E-mail: alexandresabarretto@ gmail.com. ORCID: https://orcid.org/0000-0002-7846-5145. Lattes iD: lattes.cnpq.br/0137944963846547. Niterói, Brasil.

II Artista-pesquisador, mestre e doutorando em Artes pelo PPGARTES/UERJ. Desenvolve sua pesquisa com financiamento da bolsa FAPERJ-DSC. Contemplado com o Prêmio Funarte Respirarte 2020, Leolello Berti 2019, entre outros. Indicado ao Prêmio Pipa 2021. Discente da Universidade do Estado do Rio de Janeiro - Rua São Francisco Xavier, 524 - Maracanã, Rio de Janeiro - RJ, 20943-000. E-mail: joaopauloracy@gmail.com. ORCID: https://orcid. org/0000-0002-8294-6902. Lattes iD: https://lattes.cnpq.br/2564569022169166. Rio de Janeiro, Brasil. 
A construção semântica do tecido urbano de uma cidade está sempre em movimento, através de um conjunto imbricado de relações que são estabelecidas a partir de diversos eixos: econômicos, políticos, sociais, culturais e históricos. No caso do Brasil, considerando sua formação colonial e sua inspiração nos modelos advindo de outros países que não necessariamente estabeleciam aproximações geográficas, estruturais e climáticas, tais processos de redimendisonamento das cidades e de seus trânsitos não ocorreram de maneira apaziguada. Embora seja sabido que qualquer reforma urbanística guarda consigo uma carga considerável de violência, no nosso caso, um certo descompromisso ético e político, encoberto por regimes discursivos de poder que priorizavam a manutenção de uma estrutura latifundiária e em certo sentido, colonialista, agravou de forma inconteste alguns desses momentos.

No Rio de Janeiro, que foi capital do país por 197 anos, de 1763 e 1960, devido a sua localização privilegiada e a proximidade do Oceano Atlântico para a exportação do ouro, tais mudanças e mutações foram sentidas de maneira mais potente desde o final do período colonial até a república. A cidade se apresentava como um caldeirão de corpos, hábitos, culturas e raças, sem que isso, obviamente, implicasse uma absoluta democratização do espaço público. Sendo assim, os casos de pequenos deslocamentos, mudanças e reestruturações no próprio fluxo da cidade não foram poucos. Mas nada comparável à reforma de Pereira Passos, fortemente incentivada pelo Presidente Rodrigues Alves, que começou em 1903 e foi inspirada na reforma de Paris, promovida por Georges-Eugène Haussmann entre 1853 e 1870.

A reforma Pereira Passos tinha como objetivo adequar a cidade à lógica da metrópole, bem como produzir uma certa ampliação de seus eixos viários para a inserção de novas redes de mobilidade. Obviamente havia um desejo de expansão da cidade de modo a preparar e receber um processo de modernização já em andamento que conseguisse, de maneira "generosa" acolher o escoamento de uma produção tecnológica, automobilística e urbanística em vias de consolidação, bem como produzir como imagem, o paradoxal imaginário de um espaço urbano que estivesse em absoluta consonância com os ideais de progresso material e com o complexo ideário de civilização.

Embora ainda haja uma certa disputa narrativa sobre esta reforma e sobre as proposições do prefeito Pereira Passos para o redimensionamento e a redescoberta da cidade, como por exemplo em André Nunes Azevedo (2016) que, mesmo reconhecendo a carga considerável de violência investida e utilizada em tais reformas, defende a possibilidade de compreensão de tais desejos como algo próximo de uma estruturação quixotesca da política pública que 
atendia a uma certa utopia desenvolvimentista daquele momento, apesar de suas falhas inevitáveis. De todo modo, é impossível e inadmissível que não consideremos ainda hoje, um efeito inconteste de tal processo: a especulação imobiliária e o enorme quantitativo de remoções. Elementos esses que não por acaso, se aproximam de maneira geral, da reforma parisiense e de sua forçosa desestruturação subjetiva que torna a experiência na cidade, até que a estranheza se torne familiar, um experimento de desassossego e desamparo.

Nesse sentido, é possível ponderar que tal experiência de desorientação e desterro terminam provocando, a partir de um coletivo de experiências individuais, uma sensação e um imaginário de cidade em trânsito que se estabelece pela ausência de reconhecimento e pela descoberta intermitente de novas configurações, eventualmente violentas. "Parece haver uma imagem pública de qualquer cidade que é a sobreposição de muitas imagens individuais. Ou talvez exista uma série de imagens públicas, cada qual criada por um número significativo de cidadãos[... $]^{1}$

De todo modo, é ainda fundamental explicitar que, mesmo com sua carga de potência e de mutabilidade, a experiência urbanística fruto da reforma de Pereira Passos é extremamente distinta das reformas que a cidade do Rio de Janeiro atravessou nos últimos anos quando sediou a Copa do Mundo em 2014 e os Jogos Olímpicos em 2016. Tal diferença não se dá apenas pela óbvia diferença temporal; mas fundamentalmente pelos agentes envolvidos em tais processos. Se antes o interesse era uma certa adequação ao ideário de modernidade, as últimas reformas atendiam a um jogo político específico que potencializaram uma herança higienista sem planejamento urbanístico à longo prazo que considerava o espaço público como uma experiência dicotômica e consideravelmente separatista, fruto da ditadura militar brasileira. Tratou-se de uma prática de reforma superficial da cidade, de forma a construir uma imagem adequada e consideravelmente frágil do seu espaço público, encobrindo obviamente uma estrutura e um método de funcionamento que continuava a ampliar a diferença entre os eixos mais ricos e mais pobres, construindo eventuais espaços fictícios de convívio, justificados pela lógica capital. É fundamental não esquecer que foi exatamente entre os anos 1960 e 1970 que grande parte das favelas começam a ser removidas de modo a adequar tal espaço público a uma política desenvolvimentista verticalizada que estabeleceu os balizadores econômicos que foram determinantes para a instauração de uma política neoliberal a 
partir dos anos 1980. Se na primeira metade do século XX, priorizava-se uma experiência de remodelação cultural e estética, na segunda metade do mesmo século, é iniciado um processo de outro de capitalização da experiência pública amparado por um certo empreendedorismo urbano que atendia não somente os interesses governamentais como também os negócios dos grandes conglomerados e das empreiteiras que, cada vez mais, se instauraram como agentes políticos no espaço público.

Na última década, diversas obras reconfiguraram o tecido urbano, sobretudo por conta dos Jogos Olímpicos de 2016. Sob o pretexto da construção de um suposto legado para a cidade, comunidades inteiras foram total ou parcialmente expropriadas. Entre elas está a Favela do Metrô, também conhecida como Metrô-Mangueira, por sua proximidade com a linha 2 do metrô e com o Morro da Mangueira, na Zona Norte da cidade, que já chegou a abrigar mais de 600 famílias. Em 2010, pressionadas por agentes da administração municipal, cerca de 100 famílias sucumbiram a um acordo de reassentamento, sendo obrigadas a se mudar para conjuntos habitacionais nos bairros de Cosmos e Santa Cruz, na extrema zona oeste da cidade, a horas de distância de seus antigos lares. Os moradores que resistiram à primeira investida do governo passaram a conviver com ruínas e escombros deixados pelas primeiras demolições, que pareciam ter sido estrategicamente distribuídas pelo terreno. Além disso, os moradores passaram a sofrer com cortes no fornecimento de água e energia elétrica, assim como com a suspensão do serviço de coleta de lixo.

Não por acaso, esses fatores contribuíram para que um cenário urbano caótico se estabelecesse na região, ao privar uma comunidade de serviços básicos para a manutenção de sua higiene e, por consequência, de sua saúde e submetê-la a conviver com destroços de sua própria história. Os governos (federal, estadual e municipal) pareciam querer desmontar o sistema enunciativo e a capacidade de questionamento às decisões administrativas de seus moradores, e, com isso, implodir sua capacidade de articulação comunitária.

Falta de informações sobre os projetos, falta de definição de trajetos, implementação de obras sem qualquer debate público nem possibilidade de apresentação de alternativas, procedimentos individualizados e negociados 'caso a caso', formas diversas de pressão e ameaças, falta de retirada de entulho das casas demolidas, indenizações insuficientes para que as famílias pudessem acessar uma moradia alternativa - várias foram as denúncias de violações do direito à moradia nas remoções relacionadas à implantação do projeto Rio Olímpico $[\ldots]^{2}$ 
Outra comunidade que foi duramente atingida por esse contraditório projeto de remodelação urbanística foi a Vila Autódromo, em Jacarepaguá, zona oeste da cidade. Esta antiga vila de pescadores tem sua história iniciada no final dos anos 1960, formada em sua maioria por construtores do autódromo da região, chegou a contar com cerca de 3000 moradores. E como já apontava Raquel Rolnik, antes mesmo da operacionalização de tais desapropriações "[...] Esses moradores habitam o local há mais de trinta anos e já possuem o direito legal do uso da terra (concessão de direito real de uso para fins de moradia), mas agora se encontram ameaçados de remoção"3. Assim como a Favela do Metrô, a região sofreu com uma exacerbada especulação imobiliária, principalmente por sua proximidade ao que viria a ser o complexo de arenas e equipamentos que sediou grande parte das provas olímpicas dos Jogos de 2016, além da Vila Olímpica, que abrigou os atletas durante o evento.

É neste entrecruzamento de forças e interesses que o trabalho de João Paulo Racy se coloca como um agente poético e político para pensar e refletir criticamente sobre o processo de gentrificação da cidade, a partir de um conjunto de trabalhos que denunciam, sem apostar em uma militância estrita, espaços subjetivos em desconstrução que são inevitavelmente, reflexos de um processo de transformação econômico-política da cidade. João Paulo Racy vem, ao longo dos últimos anos, desenvolvendo um trabalho que discute de forma expandida o encontro e o desencontro possíveis entre a cidade e a paisagem, escavando, através de uma pluralidade de meios, as formas plausíveis de abordar em imagem, numa deambulação poética entre o tecido urbano e aquilo que se espelha como reflexo e atmosferas em trânsito.

Esse desencontro fadado ao fracasso, fruto de um legado histórico da ruína decorrente do processo feroz de urbanização, termina por produzir uma falha e uma falta nas quais a imagem se precipita de maneira ainda volátil. E é, neste fosso poético disjuntivo que o artista opera, como se aguardasse ali, no subsolo recôndito das coisas, o instante exato para disparar novamente, através de uma sensibilidade corpórea muito específica, situações, fotografias, vídeos e objetos. E é neste mesmo espaço-tempo consideravelmente grave que somos lançados enquanto espectadores. Trata-se de uma aposta generosa e crítica de investimento mútuo (artista e público) na busca 
incansável de alguma individuação e singularidade a partir da gentrificação inevitável do agora do mundo.

Se a fotografia e o vídeo são linguagens fundamentais em sua trajetória, é possível dizer que tal uso jamais foi etnográfico, como é possível detectar em alguns outros artistas de sua mesma geração. Há, de modo muito natural, uma reviravolta semântica nas imagens produzidas que apontam, sem nenhuma afirmação ansiosa, para um caminho de amplitude e obsolescência do próprio enquadramento, do próprio olhar que nada vê; num exercício épico e mínimo de perda do aparelho diante da infinitude daquilo que lhe escapa tragicamente, de todos os elementos que jamais serão colhidos e que terminam por fundamentar o real poético e semântico que inunda sua prática.

Por outro lado, não se trata de uma epopeia desesperançada, mas de um espaço de puro devir no qual a imagem desconfia de si mesma, para que assim, possa novamente retomar seu exercício de aparecimento, desaparecimento e inevitável saudade. A forma outrora prevista e esperada por sua potência fálica, reencontra aqui, de maneira sussurrada, seu ninho e seu abismo, como um útero cálido que gesta, de forma silenciosa, seus próximos e inusitados movimentos.

Entre os anos de 2011 e 2016 o artista visitou periodicamente algumas dessas regiões que foram total ou parcialmente demolidas, buscando catalogar essas paisagens efêmeras que surgiram com a transformação radical que a cidade sofreu. Essa pesquisa de campo resultou no trabalho Impropriedades, que consiste em uma série de aproximadamente 30 imagens de fachadas de alguns desses imóveis expropriados, criando um inventário de composições visuais sobre decomposições arquitetônicas para tratar de temas como gentrificação, desapropriação e desabrigo. Seguindo uma metodologia rigorosa, uma catalogação tipológica de ruínas efêmeras que redesenharam a topografia da cidade durante os anos que antecederam as Olimpíadas foi produzida.

Assim como no processo de captura dessas imagens, em que uma distância padrão entre a câmera e as fachadas foi elegida, a impressão em grande escala também foi escolhida como estratégia na intenção de distanciar também o observador. Desta forma, a compreensão da imagem como um todo só é possível a partir de um distanciamento físico de quem se propõe a acessá-la, o que proporciona uma dimensão instalativa ao trabalho.

As ampliações foram realizadas com alta resolução, porém em um papel de baixa qualidade, conhecido popularmente como lambe-lambe e utilizado 
Figura 1 João Paulo Racy. Série Impropriedades, 20112016. Fotografia, Dimensões variáveis. com frequência para a divulgação de eventos e serviços nas ruas. Esse tipo de propaganda, considerada irregular, normalmente é realizada de forma clandestina. As impressões são aplicadas sobre chassis de compensado, mesmo material utilizado nos tapumes que cercavam as diversas obras espalhadas pela cidade. A utilização desses elementos tem por intuito a articulação contextual entre a plástica da instalação e a visualidade desses espaços abandonados, por meio da precariedade de seus materiais e sua relação com as intervenções nestes espaços em transição, para então tensionar os limites entre o etéreo da imagem e a concretude da matéria.

Ermínia Maricato, professora e pesquisadora na área do urbanismo, aponta para diversos problemas presentes no planejamento urbano nas grandes cidades de países da semi-periferia, como é o caso do Brasil. Maricato identifica na importação de padrões de modelos urbanísticos do chamado "primeiro mundo", aplicados apenas em determinadas partes da cidade (assim como da sociedade), como um dos fatores que contribuem para que as grandes cidades brasileiras sejam marcadas por uma modernização excludente, reproduzindo e acentuando desigualdades e privilégios. Para a autora, "o urbanismo brasileiro (entendido aqui como planejamento e regulação urbanística) não tem comprometimento com a realidade concreta, mas
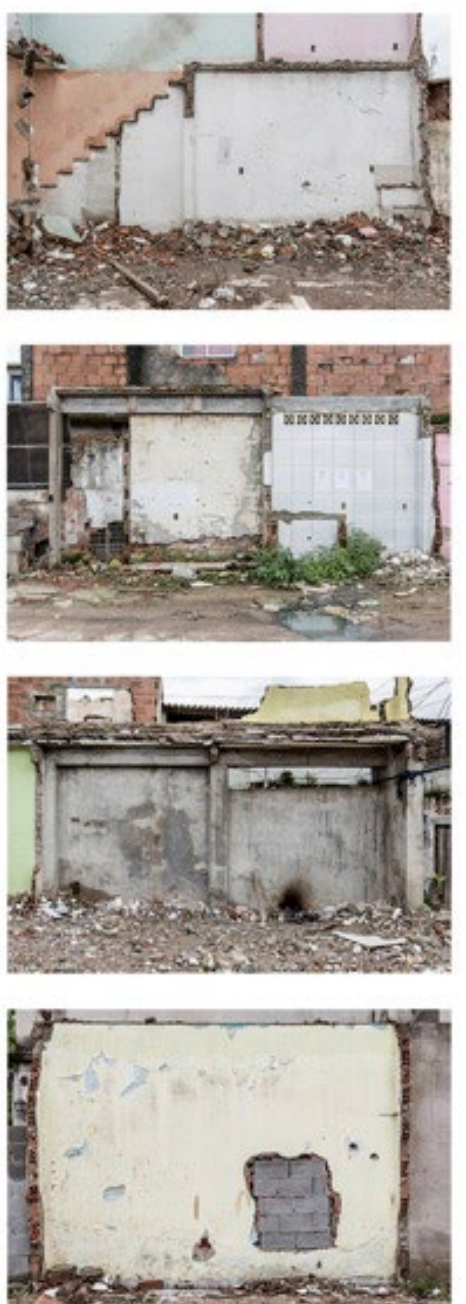
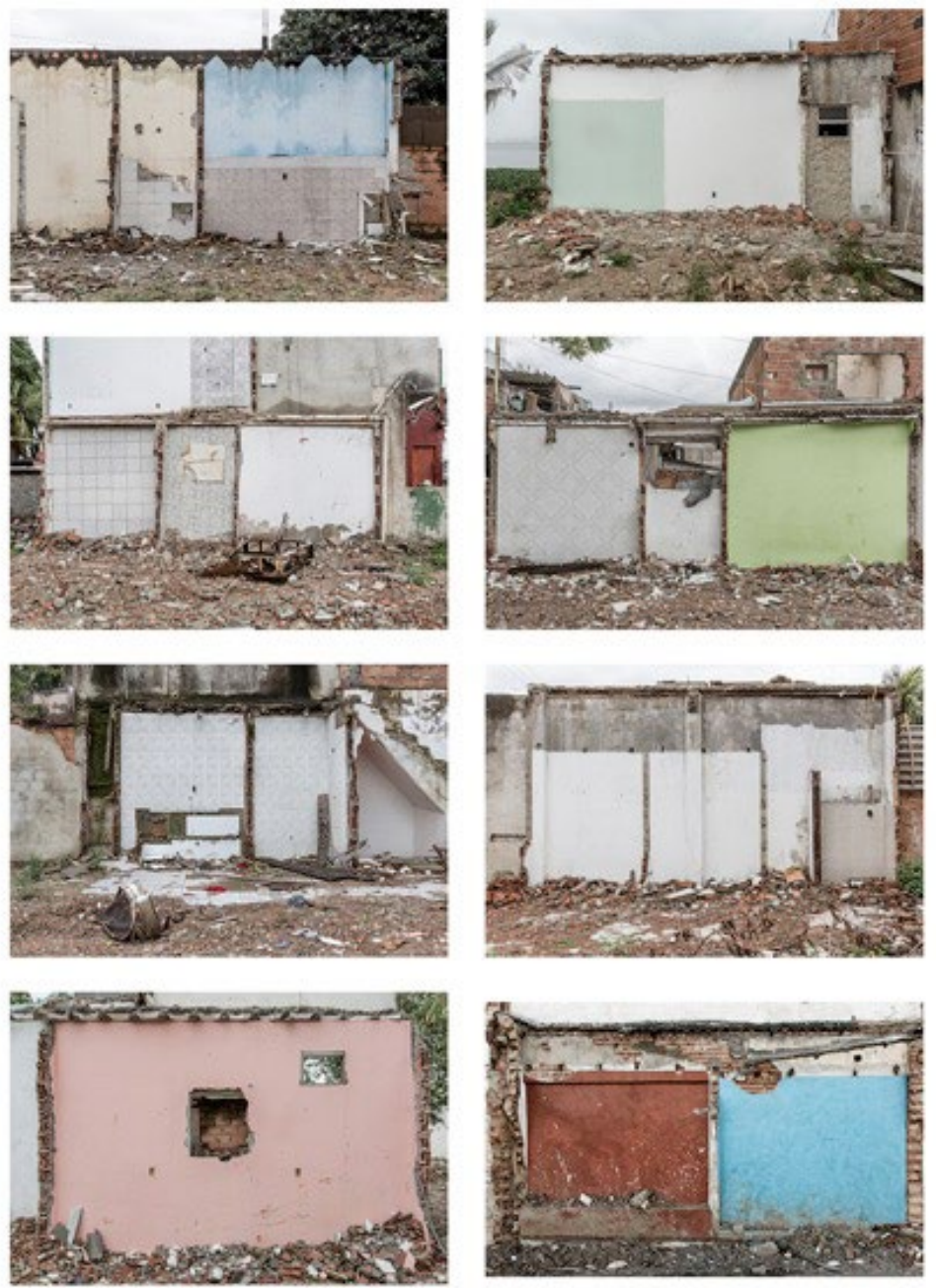

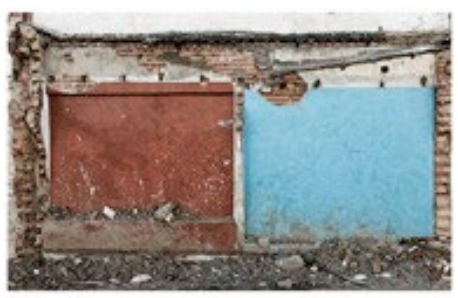

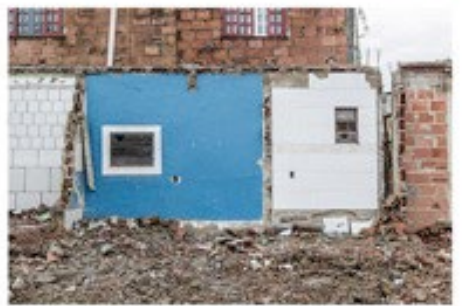
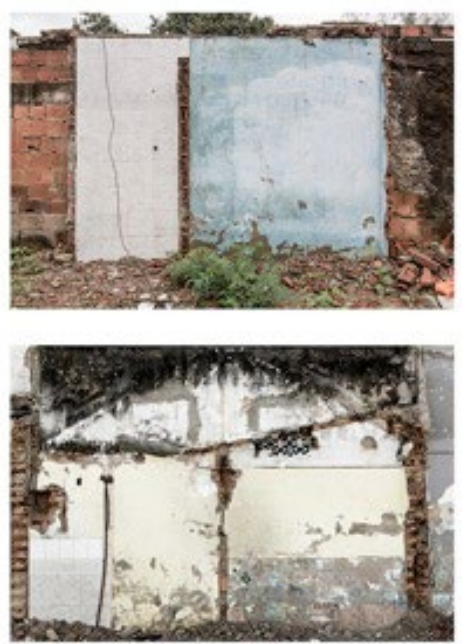

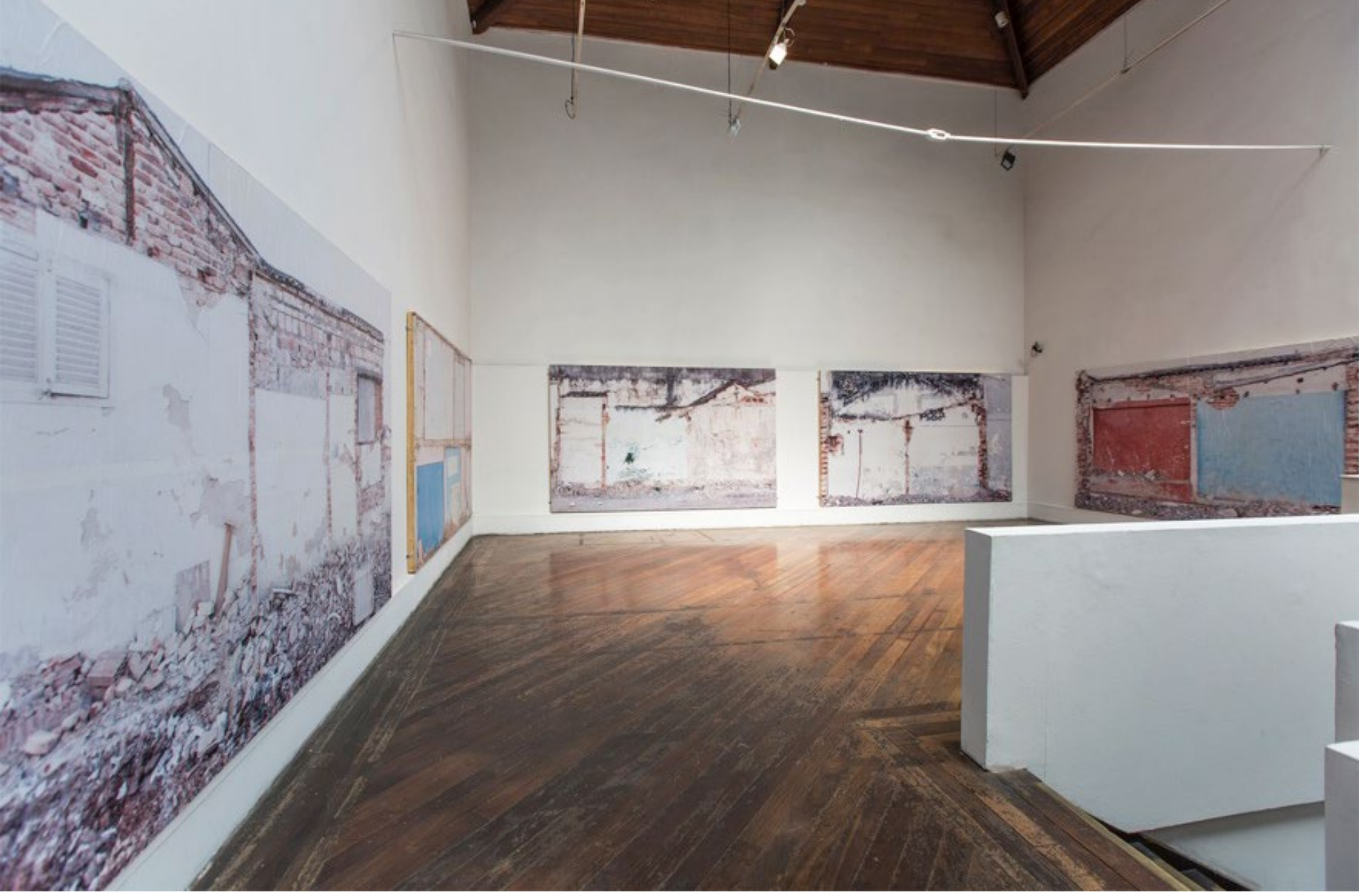

Figura 2 João Paulo Racy. Vista da exposição Impróprio, 2019. Centro Municipal de Arte Hélio Oiticica, Rio de Janeiro. Dimensões variáveis. com uma ordem que diz respeito a uma parte da cidade, apenas" ${ }^{4}$, com isso "a exclusão urbanística, representada pela gigantesca ocupação ilegal do solo urbano é ignorada na representação da 'cidade oficial'"'5. Sobre esse processo urbanístico excludente, afirma ainda a autora:

Estamos nos referindo a um processo político e econômico que, no caso do Brasil, construiu uma das sociedades mais desiguais do mundo, e que teve no planejamento urbano modernista/funcionalista importante instrumento de dominação ideológica: ele contribui para ocultar a real e para a formação de um mercado imobiliário restrito e especulativo. Abundante aparato regulatório (leis de zoneamento, código de obras, código visual, leis de parcelamento do solo etc.) convive com a radical flexibilidade da cidade ilegal, fornecendo o caráter da institucionalização fraturada, mas dissimulada.6

Outro elemento importante para a compreensão da construção da cidade, a partir de políticas públicas excludentes, é o Morro do Castelo, segunda sede da cidade e pedra fundamental para a compreensão de sua configuração

4 Maricato In: Arantes et al. 2002: 122.

5 Ibid: 142.

6 MARICATO, Ermínia. Metrópole na periferia do capitalismo. São Paulo: Hucitec, 1996, p. 124. 
estrutural e social. Com vista privilegiada para a Baía de Guanabara, principal porta de entrada da cidade, o morro era um importante ponto estratégico na disputa territorial. Da guerra entre portugueses e franceses nascia a cidade de São Sebastião do Rio de Janeiro, que teve sua construção permeada pelo genocídio e ampla catequização dos povos nativos e pela intensa comercialização de negros escravizados, uma política colonizadora que impunha a pacificação através da opressão.

Assim como nas comunidades expropriadas em função dos Jogos Olímpicos e Paralímpicos de 2016, o Morro do Castelo viveu um longo período de abandono por parte dos governantes. Nos primeiros anos do século $X X$, o morro apresentava nítidos sinais dessas décadas de descaso; o Rio de Janeiro, então capital federal da jovem república, passava por um acelerado processo de transformação urbanística, capitaneado pelo então prefeito Francisco Pereira Passos, apelidado de "bota-abaixo". Sob a alegação de embelezar e civilizar a capital federal para receber grandes eventos, como a exposição Nacional de 1908, o prefeito, que recebera poderes ditatoriais do governo federal, foi responsável por grandes reformas que transformaram a cidade. Uma de suas principais obras foi a construção da Avenida Central, atual Avenida Rio Branco. O Castelo se encontrava no caminho do projeto higienista de Pereira Passos, que, para realizá-lo, ordenou que parte do morro fosse colocada abaixo. Ao final do mandato de Pereira Passos, a via já contava com 35 novos prédios e outros 85 em construção.

Apesar de muitos concorrentes ao título, o grande "algoz" do Castelo foi Carlos Sampaio que, além de prefeito da cidade entre 1920 e 1922, era engenheiro e sócio da empreiteira responsável pela demolição total do morro. Dando continuidade à estratégia de precarização territorial iniciada por seus antecessores, o prefeito-empreiteiro investiu em propagandas que defendiam a demolição, alegando que ela traria modernização e higienização necessárias para a região. A desapropriação deixou milhares de pessoas desabrigadas.

Apesar de o desmonte do morro ter acontecido há quase um século, a região permanece até hoje conhecida como Castelo. Porém, suas novas fronteiras se tornaram invisíveis e cambiantes. O único vestígio vivo é a Ladeira da Misericórdia, pequena rua estreita e íngreme, conhecida como a primeira via pública da cidade, que foi preservada como uma espécie de marco ou um anti-monumento da demolição. É sobre esse importante ponto da cidade que João Paulo Racy realiza o trabalho Sob a sombra do Castelo, instalação que articula diferentes técnicas e materiais para dialogar com mitos e fatos históricos referentes à região. 
O primeiro movimento da pesquisa realizada foi uma visita à Ladeira da Misericórdia, último rastro tangível da memória de um lugar que resistiu por séculos ao abandono ao qual foi submetido. A ladeira termina em um corte abrupto, uma ferida cicatrizada pela história, escondida entre avenidas e quatro gerações de edifícios que constituem o centro que conhecemos hoje. Apenas seu trecho inicial foi mantido de pé, preservando o calçamento original de pedras, conhecido como "pé de moleque". Esse é o primeiro elemento utilizado na estruturação do trabalho: uma pedra retirada do ponto mais alto da primeira e última via de acesso ao Morro do Castelo. A pedra é colocada sobre um mapa da região, na época em que sofreu o primeiro corte estrutural para a construção da Avenida Central, preenchendo o espaço exato que o morro ocupava no mapa antes de sofrer o desmonte.

Durante a pesquisa de campo, o entorno da área atualmente compreendida como Castelo foi visitado periodicamente. Em tais visitas o artista levou consigo algumas cópias impressas do mapa atual da região. No decorrer desse processo, algumas dezenas de pessoas nas ruas foram abordadas e Ihes foi pedido que marcassem no mapa onde supunham estar o Castelo, sem que maiores explicações fossem dadas. O único método comum entre todas as respostas foi a utilização de uma caneta vermelha para a marcação imaginária, o que proporcionou um contraste visual com a impressão monocromática das cópias.

Ao frequentar diariamente a região que já foi o mais importante morro da cidade e que hoje se encontra no mesmo nível do mar, o artista passa a se questionar sobre qual teria sido o destino daquelas muitas toneladas de um terreno tão simbólico, disputado por gerações. Entre as regiões que foram modificadas utilizando as terras do castelo, estão parte dos bairros da Urca, do Jardim Botânico, da Lagoa Rodrigo de Freitas e outras áreas baixas ao redor da Baía de Guanabara, entre elas, o terreno que abriga o Aeroporto Santos Dummont.

Interessado nas possíveis relações entre o Castelo e esses lugares, foram incluídos esses desdobramentos geológicos do Castelo em seus deslocamentos diários. Conectadas por um solo disputado durante séculos e marcado pelo sangue e suor de gerações de habitantes, essas regiões têm em comum estarem em localizações consideradas "nobres", erigidas a partir de um terreno retirado à força de um local abandonado pelo poder público e transferindo para áreas com grande potencial de valorização - uma forma brutal de aplicar a noção de mais valia a um território. Nesse caso, para além da localização geográfica, a própria materialidade do terreno foi transformada em commodity. 
Figura 3

Sob a sombra do Castelo, 2019. Centro

Municipal de Arte Hélio Oiticica, Rio de Janeiro. Instalação.
Seguindo as pistas dessa lógica de cidade-moeda, foram recolhidas amostras do solo de quatro regiões que têm em suas bases terras do Morro do Castelo: Urca, Jardim Botânico, Lagoa e Aeroporto Santos Dumont. Essas amostras foram acondicionadas separadamente em recipientes de vidro, identificadas através de etiquetas e agregadas ao trabalho. A ação parte do interesse em trazer uma porção do terreno removido de volta à região central da cidade e apresentá-los de forma expositiva para discutir possíveis origens da gentrificação no contexto histórico da cidade. O último elemento incorporado à instalação foi um dos responsáveis por seu título - uma fotografia que retrata a silhueta de uma construção em formato de castelo, projetada sobre um muro de pedra. Trata-se da sombra do prédio que abriga o Real Gabinete Português de Leitura, edificação com formas semelhantes às de um castelo. A composição sombria, proporcionada pela incidência do sol sobre a face costal desse prédio histórico, durava poucos minutos.

A reunião desses elementos, produzidos separadamente, mas costurados por um fio-condutor histórico, social e político, possibilitou a construção da 
instalação que foi apresentada na exposição Em Torno - Rio de Janeiro, realizada também no Centro Municipal de Artes Hélio Oiticica no Rio de Janeiro. As amostras de solo, a fotografia da "sombra do castelo", a pedra repousada sobre o mapa do início do século XX e uma prancheta com impressões do mapa atual foram distribuídas sobre uma mesa, criando uma composição formal e metódica. Na parede acima da mesa, os mapas marcados pelos passantes foram distribuídos em formato de grade, criando um mosaico de possibilidades de reinterpretação sobre os limites e fronteiras da região conhecida até hoje como Castelo.
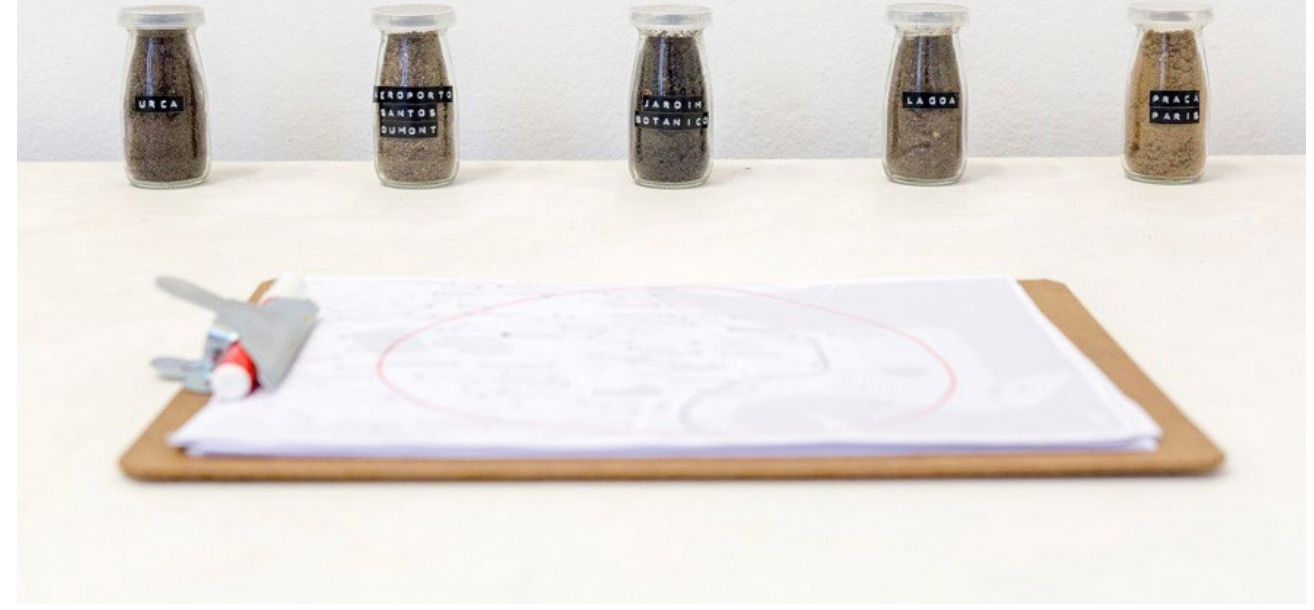

Muitos dos projetos de urbanização apresentados por diferentes governos ao longo da história da construção da cidade tinham entre seus principais interesses a especulação financeira de regiões até então desvalorizadas. Entre essas operações está o projeto Porto Maravilha, que consistiu em um conjunto de intervenções, obras e serviços realizados na zona portuária da cidade com a proposta de uma dita revitalização da região. Viabilizado em um contexto de preparação da cidade para os Jogos Olímpicos e Paralímpicos de 2016, o projeto envolveu os setores de transporte, infraestrutura urbana, habitação e cultura, através de recursos públicos e privados.

A esse tipo de projeto urbano é dado o nome de planejamento estratégico, modelo que vem sendo exportado para diversas cidades do mundo, como afirma o urbanista Carlos B. Vainer, ao dizer que: 
Entre os modelos de planejamento urbano que concorrem para ocupar o trono deixado vazio pela derrocada do tradicional padrão tecnocrático - centralizado - autoritário está o do chamado planejamento estratégico. O modelo vem sendo difundido no Brasil e na América Latina pela ação combinada de diferentes agências multilaterais (Bird, Habitat) e de consultores internacionais, sobretudo catalães, cujo agressivo marketing aciona de maneira sistemática o sucesso de Barcelona. ${ }^{7}$

Fruto da política neoliberal e inspirado em conceitos oriundos do planejamento empresarial, este modelo de urbanismo fomenta a competição entre as cidades na busca por investimentos e tecnologia. Assim sendo, essas cidades passam a ter como agente norteador o lucro, agindo estrategicamente como empresas e tomando decisões a partir das expectativas geradas pelo mercado. Nesse contexto, o Estado passa a agir de acordo com os interesses financeiros e dependendo das exigências das empresas envolvidas, o que acarreta em uma despolitização dessas cidade-empresas e na subordinação do poder público às exigências do mercado.

A dita revitalização desses espaços urbanos altera as dinâmicas de sua composição, trazendo consigo um efeito de migração da população que ali habitava por novos moradores que podem arcar com os custos mais altos de bens e serviços que esses lugares passam a ter. Esse processo gentrificador não só "expulsa" os habitantes originais desses lugares, como também os transforma em espaços homogeneizados, apagando suas características tradicionais em prol de uma padronização estética. Sob o efeito desse processo, regiões em diferentes estados ou países passam a ter a mesma aparência, perdendo boa parte de suas referências culturais.

Tais pesquisas de campo vêm contribuindo para a construção de uma investigação que se propõe a tratar de pontos de aproximação e distanciamento entre as motivações e efeitos de duas diferentes reformas urbanísticas sofridas pela cidade do Rio de Janeiro, o desmonte do Morro do Castelo e o projeto Porto Maravilha, além das possibilidades de elaboração de uma narrativa que lide com tais acontecimentos sob uma ótica poética e conceitual. Em comum, ambos projetos se deram de forma violenta e em prol de interesses outros que não o bem estar da população que habitava os espaços onde elas aconteceram. Com isso, é possível considerar que, historicamente, o planejamento urbanístico da cidade se dá de forma desigual e a partir de lógicas gentrificadoras que alicerçam e solidificam o binômio centro - periferia, tratando o território urbano como commodity e favorecendo interesses de grupos que se beneficiam com a especulação imobiliária.

7 VAINER In: ARANTES, Otília et. al. A cidade do pensamento único: desmanchando consensos. Petrópolis: Vozes, 2002, p. 75. 


\section{Referências}

ARANTES, Otília et. al. A cidade do pensamento único: desmanchando consensos. Petrópolis: Vozes, 2002.

AZEVEDO, André Nunes. A grade reforma urbana do Rio de Janeiro : Pereira Passos, Rodrigues Alves e as ideias de civilização e progresso. Rio de Janeiro: Editora PUC-Rio, 2016.

LYNCH, Kevin. A imagem da cidade. São Paulo: Martins Fontes, 1999.

MARICATO, Ermínia. Metrópole na periferia do capitalismo. São Paulo: Hucitec, 1996.

ROLNIK, Raquel. Guerra dos lugares. São Paulo: Boitempo Editorial, 2015. 